\title{
A New Design for Compact Size Wireless Power Transfer Applications Using Spiral Defected Ground Structures
}

\author{
Rasha HUSSEIN ${ }^{l}$, Hany A. ATALLAH ${ }^{1}$, Sherif HEKAL ${ }^{2}$, Adel B. ABDEL-RAHMAN ${ }^{1,3}$ \\ ${ }^{1}$ Electronics and Communications Engineering, Electrical Engineering Dept., Faculty of Engineering, \\ South Valley University, Qena 83523, Egypt \\ ${ }^{2}$ Electronics and Communications Engineering Dept., Faculty of Engineering at Shoubra, \\ Benha University, Shoubra, Egypt \\ ${ }^{3}$ Egypt-Japan University of Science and Technology, Alexandria 21934, Egypt
}

Rasha.h.ahmed@eng.svu.edu.eg, h.atallah@eng.svu.edu.eg, sherif.salah@feng.bu.edu.eg, adel_b15@yahoo.com

Submitted February 24, 2018 / Accepted September 6, 2018

\begin{abstract}
In this article, a new wireless power transfer (WPT) design is proposed for improving the efficiency of the system. The suggested system contains two spiral defected ground structure (DGS) resonators coupled back-toback. A band-pass filter is then to be designed for the wireless power to be transferred from the transmitter unit to the receiver unit. The DGS resonators are loaded through chip capacitors for miniaturization. The proposed structures are fabricated and tested. The proposed system has the highest efficiency of $97.7 \%$ at a transmission distance of $10 \mathrm{~mm}$ which is suitable for biomedical applications. Both simulated and experimental results are in good concurrence.
\end{abstract}

\section{Keywords}

Defected ground structure (DGS), spiral, wireless power transfer (WPT)

\section{Introduction}

The technology of wireless power transfer (WPT) has attracted a significant concentration in recent days that caused by the growing demand of the wireless applications like portable electronic devices, biomedical implants, and wireless buried sensors. It is not impossible to transfer energy over an air without any cables by WPT [1]. WPT is an extremely useful technology that has numerous applications and benefits. Cell phones, laptops, and other mobile devices could function without ever having to be plugged in, cars could drive on highways burning no fossil fuels; wireless power even has the potential to solve much of the renewable energy issues [2], [3], [4], [5]. The energy between the two parts of the system can be conveyed through an air in WPT by the fields produced by the charged of particles. The air gap is linked by renovating the energy into a shape that can transportable over the air. In the receiver, the operable electric current can be obtained from the energy which is transformed into an oscillating field which can be transferred through the air. The energy can be transmitted through an electric field, magnetic field, or electromagnetic (EM) field such as microwaves, radio waves, or even light. The classification of the WPT system can be classified according to power and distance between the transmitter and the receiver [2]. Different implementation techniques of WPT are investigated using the nearfield (inductive/capacitive) coupling techniques and the farfield (RF/Microwaves/Laser beams) radiative techniques [3], [6].

Defected ground structures (DGSs) are the slots or the defects which are incorporated on the ground plane of microwave planar circuits. Placement of DGS resonators under the transmission line introduces changes in the propagation of the waves along the line enhancing some parameters in the circuit. Moreover, new materials like the artificial materials can be used to improve the characteristics of the microwave planar circuits like filters [7] and antennas [8] and also to be suitable for transmission of the high data rate. This technique can be used to improve the performance of the WPT systems.

\begin{tabular}{|l|l|l|l|l|}
\hline Technology & Range & Frequency & $\begin{array}{l}\text { Antenna } \\
\text { type }\end{array}$ & Applications \\
\hline $\begin{array}{l}\text { Inductive } \\
\text { coupling }\end{array}$ & Short & Hz-MHz & $\begin{array}{l}\text { 3-D wire } \\
\text { loops and } \\
\text { helical } \\
\text { antennas }\end{array}$ & $\begin{array}{l}\text { Induction heater } \\
\text { cookers circuits, } \\
\text { charging electric } \\
\text { vehicles, and } \\
\text { electric } \\
\text { toothbrush }\end{array}$ \\
\hline $\begin{array}{l}\text { Resonant } \\
\text { inductive } \\
\text { coupling }\end{array}$ & Mid- & MHz-GHz & $\begin{array}{l}\text { Tuned wire } \\
\text { poils and } \\
\text { resonant } \\
\text { spirals }\end{array}$ & $\begin{array}{l}\text { Charging } \\
\text { portable devices, } \\
\text { biomedical } \\
\text { implants, RFIDs, } \\
\text { and smart cards. }\end{array}$ \\
\hline $\begin{array}{l}\text { Capacitive } \\
\text { coupling }\end{array}$ & Short & $\mathrm{kHz}-\mathrm{MHz}$ & $\begin{array}{l}\text { Electrodes } \\
\text { portable devices } \\
\text { and smart cards. }\end{array}$ \\
\hline $\begin{array}{l}\text { RF and } \\
\text { microwaves }\end{array}$ & Long & $\mathrm{GHz}$ & $\begin{array}{l}\text { Rectenna } \\
\text { and phased } \\
\text { arrays }\end{array}$ & $\begin{array}{l}\text { Solar power } \\
\text { satellites and } \\
\text { powering drone } \\
\text { aircraft }\end{array}$ \\
\hline Light waves & Long & THz & $\begin{array}{l}\text { Laser } \\
\text { beams, } \\
\text { lenses, and } \\
\text { photocells }\end{array}$ & $\begin{array}{l}\text { Powering drone } \\
\text { aircraft using } \\
\text { photovoltaic cell } \\
\text { panels }\end{array}$ \\
\hline
\end{tabular}

Tab. 1. The different techniques of WPT. 
In [7], the authors studied the H-shaped resonators for WPT system at $5 \mathrm{~mm}$ distance with an efficiency of $85 \%$. However, the system size is $25 \times 25 \mathrm{~mm}^{2}$. In [2], the authors studied two different shapes of the DGS (H-shaped and semi-H-shaped) for WPT. The H-shaped DGS WPT system has a size of $20 \times 20 \mathrm{~mm}^{2}$ and an efficiency of $68 \%$ at distance of $13 \mathrm{~mm}$ while the semi-H-shaped DGS WPT system has an efficiency of $73 \%$ at a transmission distance of $25 \mathrm{~mm}$ and the total size of the system is $21 \times 21 \mathrm{~mm}^{2}$. In [8], the authors propose a new structure which contains two compact $\mathrm{C}$-shaped resonators allowing the transmission of the power without cables through $15 \mathrm{~mm}$ distance between the transmitter and the receiver with an efficiency of $69 \%$. However, the total system size is $25 \times 25 \mathrm{~mm}^{2}$. The author in [9] introduces a new design for WPT that depends on asymmetric design for the transmitter and the receiver. Furthermore, the transmitter size is $120 \times 120 \mathrm{~mm}^{2}$ and the receiver size is $80 \times 80 \mathrm{~mm}^{2}$ while the system operates at an efficiency of $54.5 \%$ and a transmission distance of $30 \mathrm{~mm}$. In [10], the author presented a system depending on a dual band antenna with resonators for biotelemetry applications. The authors in [11] are studied the most important applications for WPT and the methods for powering sensors which are embedded in buildings by using rechargeable batteries. These rechargeable batteries can be recharged using WPT.

This brief summarizes the modeling and the analysis of a WPT system using DGS resonators in Sec. 2. Section 3 presents the fabrication and the measurement of the suggested WPT system for verifications. Finally, a summary concludes the main results in Sec. 4.

\section{WPT System Modeling and Analysis}

\subsection{Single Spiral DGS Band Stop Filter}

Figure 1 shows the configuration of the suggested spiral DGS. The spiral DGS are constructed and etched on the bottom side of the substrate. The spiral DGS has a metallic width of $M s$ and the etched gab is $G_{s} s$. The $50 \Omega$ feed line is constructed on the top side and it has a width of $W_{-}$and a length of $L \_s$. The capacitor $C_{1}$ is placed at the open end of the etched spiral DGS for miniaturizing and adjusting the resonance frequency. The system is designed on Roger $3003\left(\varepsilon_{\mathrm{r}}=3\right)$ with a thickness of $0.762 \mathrm{~mm}$.

In Tab. 2, the parameters of the suggested design are listed which are used in simulation using computer simulation technology (CST) microwave studio. In Fig. 2, the equivalent circuit of the design is extracted and the frequency response is presented which is equivalent to a one pole band stop filter (BSF) operating at $0.26 \mathrm{GHz}$. The extracted equivalent circuit includes the inductances $L_{\mathrm{P}}$ which existence is due to the spiral DGS. In addition, the capacitance $C_{\mathrm{P}}$ is existent due to the SMD lumped capacitor which is inserted in the slot of the spiral DGS to operate at the resonance frequency of $260 \mathrm{MHz}$ and to minimize the design area. This resonance frequency was chosen at the low-frequency range to check the reliability of the design and to validate the theory behind the proposed idea. Additionally, to compare with other designs operating at the low-frequency ranges as investigated in [2].

Two SMD capacitors are added to the gab of the spiral DGS for improving the quality factor with miniaturized
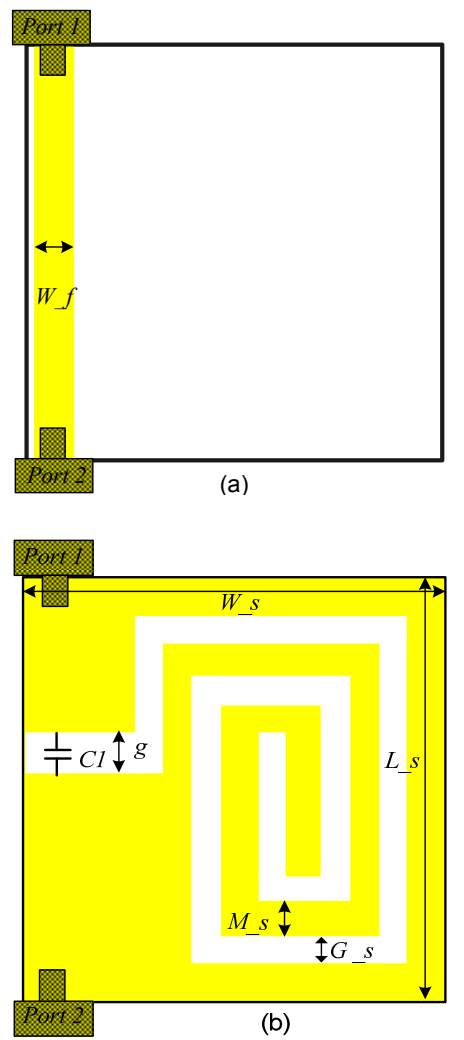

Fig. 1. Single spiral DGS. (a) Top side. (b) Bottom side.

\begin{tabular}{|c|c|}
\hline parameter & value \\
\hline$W \_\mathrm{s}$ & $20 \mathrm{~mm}$ \\
\hline$L \_s$ & $20 \mathrm{~mm}$ \\
\hline$G \_\mathrm{s}$ & $1 \mathrm{~mm}$ \\
\hline$M \_\mathrm{s}$ & $2 \mathrm{~mm}$ \\
\hline$g$ & $1.5 \mathrm{~mm}$ \\
\hline$W \_\mathrm{f}$ & $1.9 \mathrm{~mm}$ \\
\hline$C_{1}$ & $8 \mathrm{pF}$ \\
\hline$C_{2}$ & $4 \mathrm{pF}$ \\
\hline
\end{tabular}

Tab. 2. The optimized design parameters of the proposed spiral DGS.

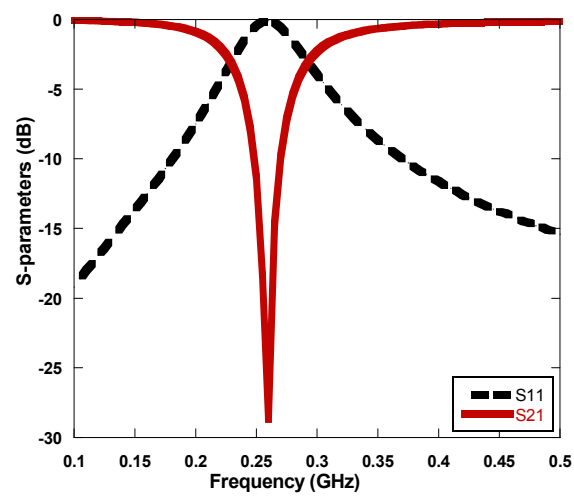

(a) 


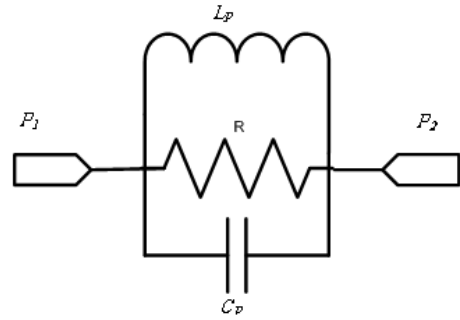

(b)

Fig. 2. The S-parameters and the equivalent circuit model: (a) S-parameters of the single spiral DGS using ADS (b) The equivalent circuit of the model.

resonator by increasing the equivalent capacitance without increasing the total size as described in [12].

\subsection{Coupled Spiral DGS WPT System}

The investigation of the two coupled spiral DGS is presented in this part. Each transmitter and receiver is constructed from the BSF that was designed in the previous section. The used single spiral DGS resonator is shown in Fig. 3 after adding the matching capacitor $C_{2}$. When two DGS resonators are coupled back to back, it results in a bandpass characteristic, and the power is transferred from the source to the load through the coupled DGS resonators. In Fig. 4(a) two coupled spiral DGS are separated from each other by a distance $h$. In the simulation part, the two resonators are separated from each other by an air with a permittivity of $\varepsilon_{\mathrm{r}}=1$. An SMD capacitor $C_{2}$ is added between the top and the bottom layer at the end of the $50 \mathrm{ohms}$ transmission line for adjusting the resonance frequency and the impedance matching as shown in Fig. 3. In Fig. 4(b) the equivalent circuit of the suggested design is presented. The equivalent circuit contains the inductances $L_{\mathrm{p} 1}$ and $L_{\mathrm{P} 2}$ (where $L_{\mathrm{p} 1}=L_{\mathrm{P} 2}$ ) which exist due to the spiral DGS in both TX and RX. In addition, the capacitances $C_{\mathrm{P} 1}$ and $C_{\mathrm{P} 2}$ (where $C_{\mathrm{P} 1}=C_{\mathrm{P} 2}$ ) are existent due to the SMD lumped capacitors which are inserted in the slot of the spiral DGS in both TX and RX. Also, the $C_{\mathrm{LS}}$ capacitor is due to the inserted series capacitor $C_{2}$ which is connected between the top and the bottom layers and used for impedance matching.

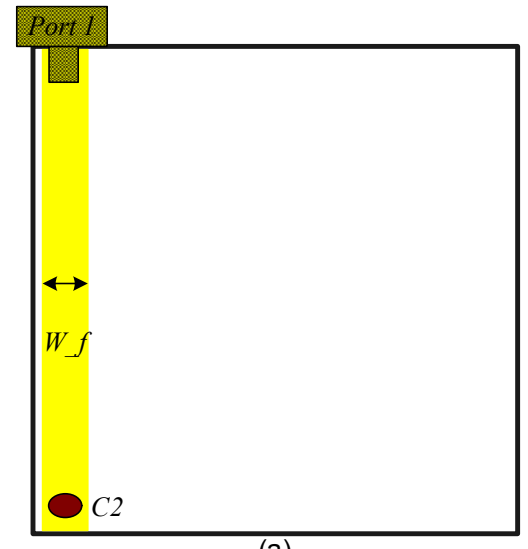

(a)

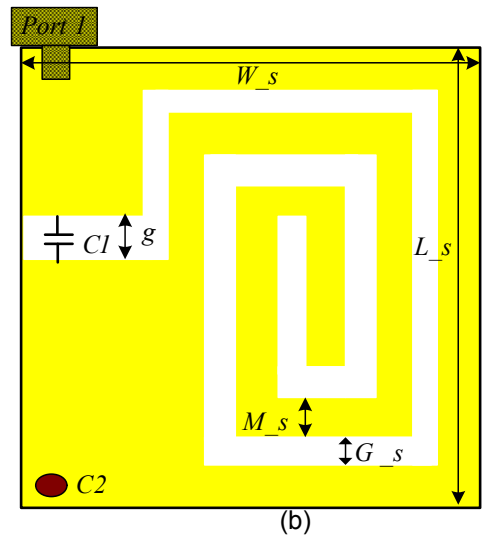

Fig. 3. The suggested spiral DGS TX/RX. (a) Top side. (b) Bottom side.

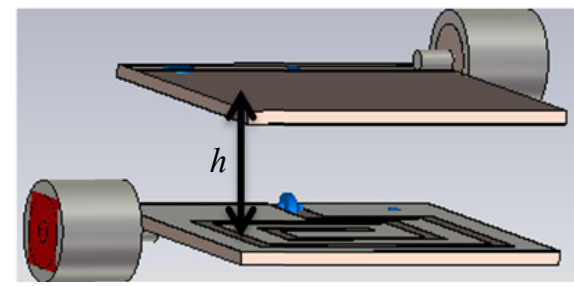

(a)

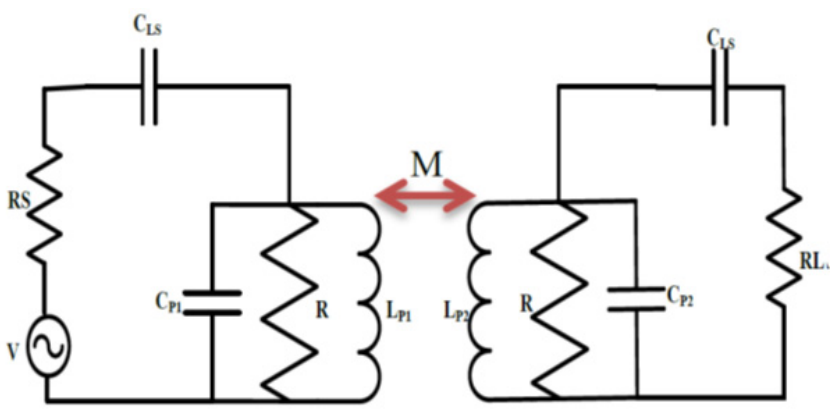

(b)

Fig. 4. The proposed WPT system. (a) 3-D view. (b) Circuit model.

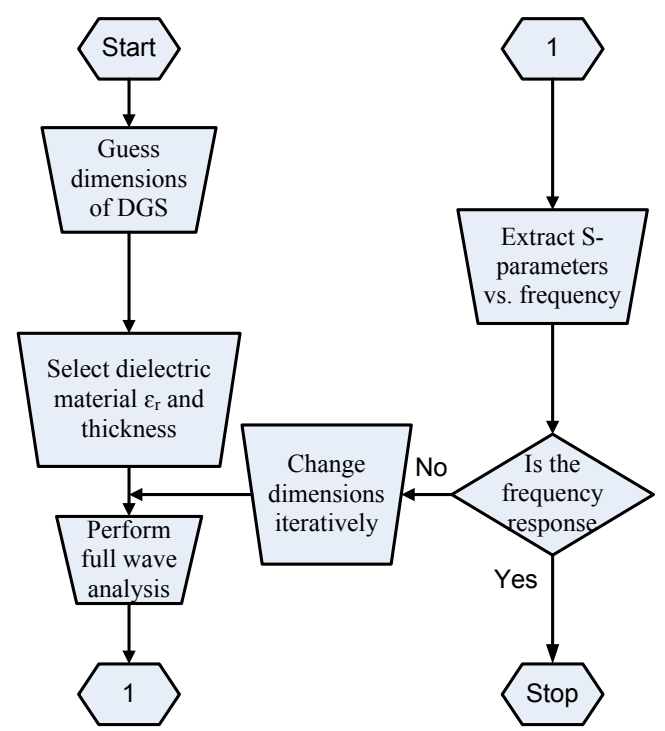

Fig. 5. Design flowchart. 


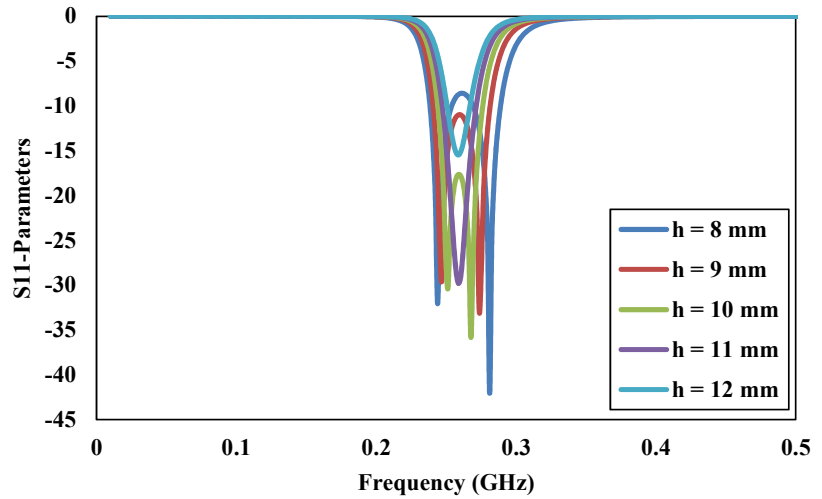

(a)

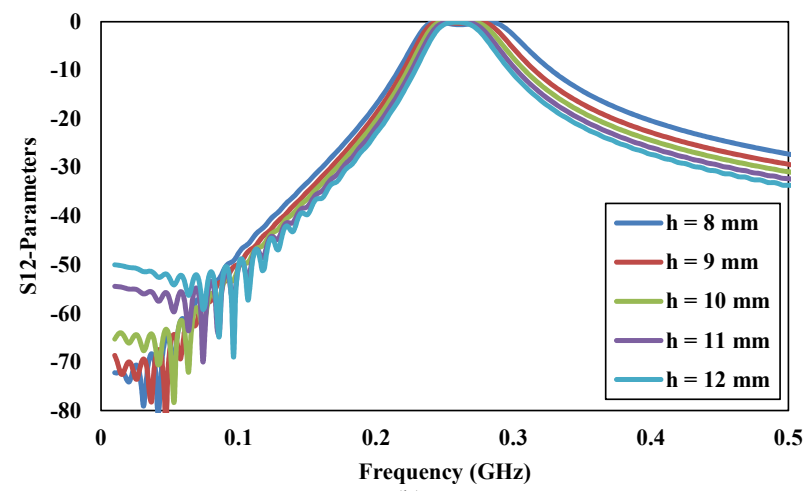

(b)

Fig. 6. The effect of the spacing $h$ on the performance. (a) $\left|S_{11}\right|$ parameters. (b) $\left|S_{21}\right|$ parameters.

The flowchart in Fig. 5 presents an analytical design procedure for the proposed WPT system. Generally, this design procedure can be used to design a DGS WPT system operating at the desired resonance frequency.

By studying the effect of the spacing $h$ between the transmitter and the receiver on the performance of the system, the spacing $h$ is varied for from $8 \mathrm{~mm}$ to $12 \mathrm{~mm}$ while the coupling varies from high to small values at the selected distances as presented in Fig. 6. The splitting appears at short distances where each resonator is acting as a load to the other with high coupling.

Figure 7 shows the magnetic field distribution that is responsible for magnetic coupling between two resonators at the operating frequency of $260 \mathrm{MHz}$ at different phases.

\section{Experimental Results}

The suggested system was simulated and optimized using CST microwave studio. The fabrication of the system was done by a photolithographic technique and the layers of the fabricated prototype are shown in Fig. 8(a) and (b). The power transfer efficiency is defined as the coupling efficiency between two resonators which is derived in [10]. For comparing the performance of the system, the suggested system's Figure of Merit (FoM) can be computed by using (2) from [12]. The measurement results are shown in Fig. 8(c) and (d) where $\left|S_{21}\right|$ equals $-0.1 \mathrm{~dB}$ and $\left|S_{11}\right|$ equals $-28 \mathrm{~dB}$. By substitution in (1), the system achieves an effi-

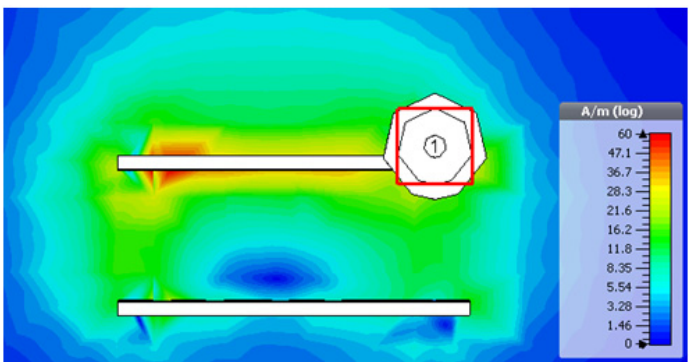

(a)

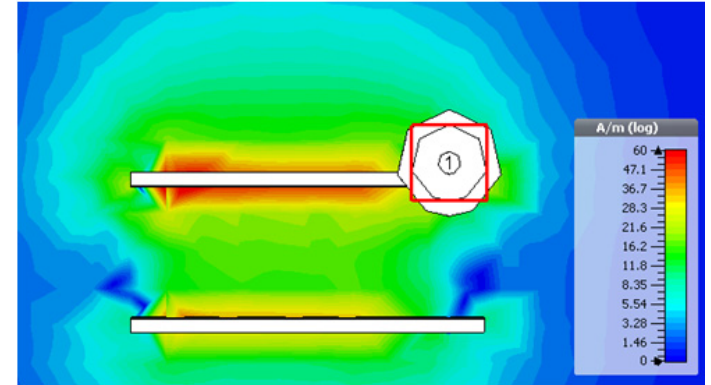

(b)

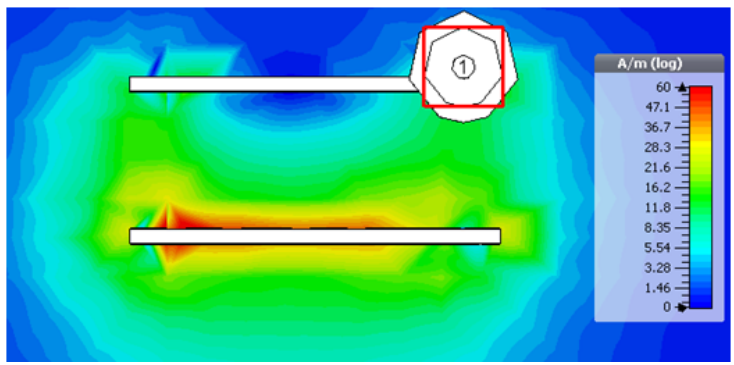

(c)

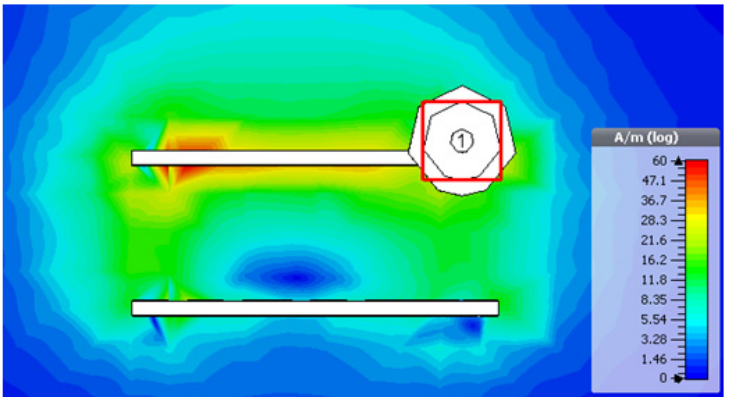

(d)

Fig. 7. Simulated magnetic field distributions of the proposed WPT system at $260 \mathrm{MHz}$ at different phases. (a) $\Phi=0^{\circ}$. (b) $\Phi=45^{\circ}$. (c) $\Phi=135^{\circ}$. (d) $\Phi=180^{\circ}$.

ciency of $97.7 \%$ at the transmission distance $h$ of $10 \mathrm{~mm}$ and the resonance frequency is $260 \mathrm{MHz}$. The total size of the system is $20 \times 20 \mathrm{~mm}^{2}$ and the achieved FoM is 0.4885 using (2). Moreover, it is obvious that there is good concurrence between EM simulations and experimental results. Table 3 presents the differences between the proposed design and the other previous work. According to the calculated FoM, the presented comparisons in Tab. 3 show that the proposed design has a good efficiency and a compact size compared to other designs. The comparisons between the suggested work and the other work such as in [9], [2], and [10] confirm that the suggested system is more compact and achieves higher FoM than the mentioned structures. Although the structure of semi-H shaped in [2] 
has high FoM but it has a large size and a low efficiency compared to the suggested work.

$$
\begin{gathered}
\eta=\left|S_{21}\right|^{2}\left[\left(1-\left|S_{11}\right|^{2}\right)\left(1-\left|S_{22}\right|^{2}\right)\right]^{0.5}, \\
F O M=\frac{\eta h}{\sqrt{L_{\text {sub }} W_{\text {sub }}}} .
\end{gathered}
$$

\section{Conclusion}

In this study, a high-efficiency compact WPT system employing spiral DGS resonators that are coupled back to back is proposed. The design theory and simulation results are in good agreement. Measurements show more than 97\%

\begin{tabular}{|c|c|c|c|c|c|}
\hline WPT system & $\begin{array}{c}\text { Frequency } \\
(\mathbf{M H z})\end{array}$ & $\begin{array}{c}\text { Size } \\
\left(\mathbf{m m}^{2}\right)\end{array}$ & $\begin{array}{c}\text { Efficiency } \\
(\mathbf{\%})\end{array}$ & $\begin{array}{c}\text { Distance } \\
(\mathbf{m m})\end{array}$ & FoM \\
\hline This work & 260 & $20 \times 20$ & 97.7 & 10 & 0.4885 \\
\hline$[7]$ & 1000 & $25 \times 25$ & 85 & 5 & 0.17 \\
\hline $\begin{array}{c}{[2]} \\
(\text { H-shape })\end{array}$ & 300 & $20 \times 20$ & 68 & 13 & 0.442 \\
\hline $\begin{array}{c}{[2]} \\
\left(\begin{array}{c}{[2] \mathrm{H}-} \\
\text { shape })\end{array}\right.\end{array}$ & 300 & $21 \times 21$ & 73 & 25 & 0.8690 \\
\hline$[8]$ & 1000 & $25 \times 25$ & 69 & 15 & 0.414 \\
\hline
\end{tabular}

Tab. 3. The differences between the suggested system with other previous works.

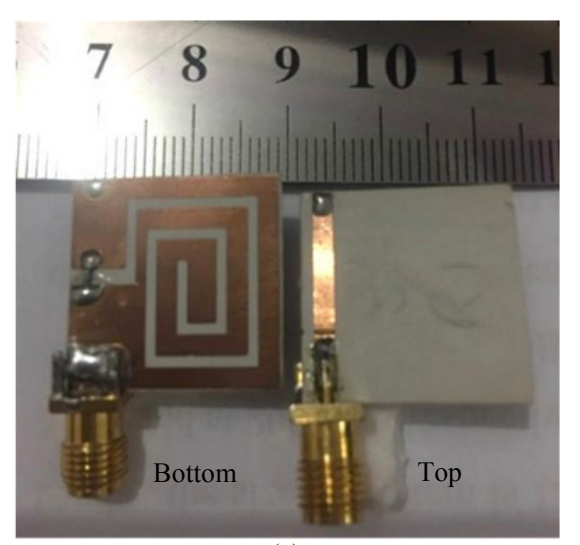

(a)

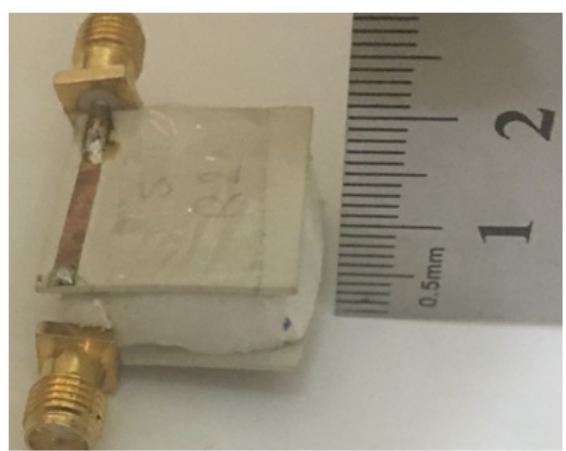

(b)

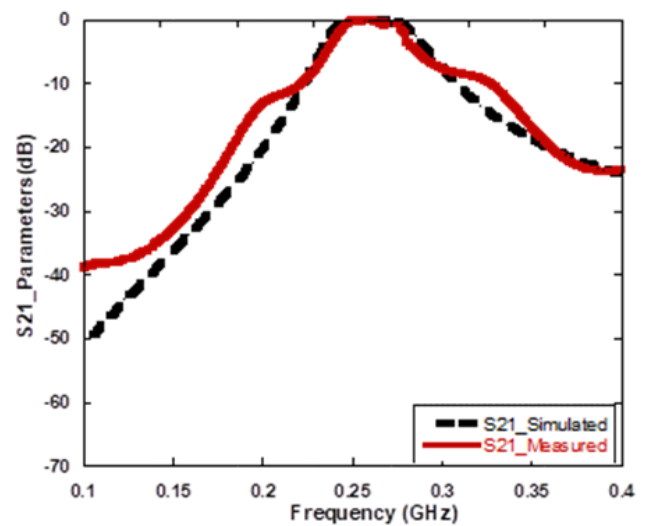

(c)

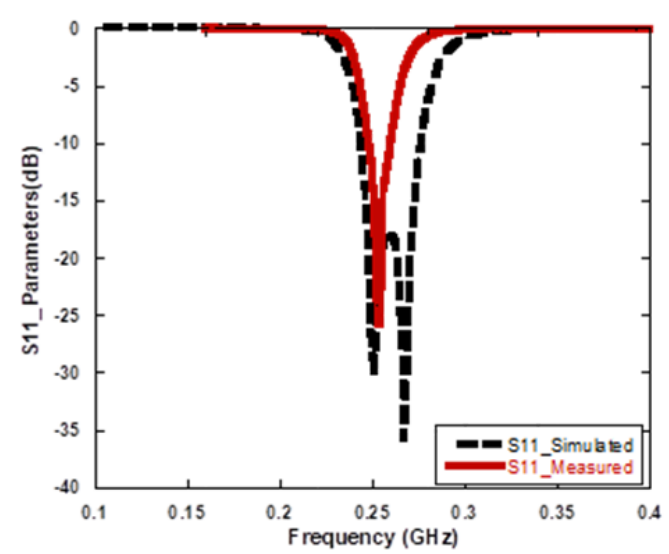

(d)

Fig. 8. The fabricated spiral DGS WPT system and the measured results. (a) The top layer and bottom layer. (b) Setting at $10 \mathrm{~mm}$ distance. (c) $\mathrm{S}_{21}$ results. (d) $\mathrm{S}_{11}$ results.

efficiency at $260 \mathrm{MHz}$ at a transmission distance of $10 \mathrm{~mm}$. This work is suitable for charging of portable electronic devices, biomedical implants, and wireless buried sensors.

\section{References}

[1] EL RAYES, M. M., NAGIB, G., ALI ABDELAAL, W. G. A review on wireless power transfer. International Journal of Engineering Trends and Technology, 2016, vol. 40, no. 5, p. 272-280. ISSN: 2231-5381

[2] HEKAL, S., ABDEL-RAHMAN, A. B., JIA, H., et al. A novel technique for compact size wireless power transfer applications using defected ground structures. IEEE Transactions on Microwave Theory and Techniques, 2017, vol. 65, no. 2, p. 591-599. DOI: 10.1109/TMTT.2016.2618919

[3] DAS BARMAN, S., REZA, A. W., KUMAR, N., et al. Wireless powering by magnetic resonant coupling: Recent trends in wireless power transfer system and its applications. Renewable and Sustainable Energy Reviews, 2015, vol. 51, p. 1525-1552. DOI: 10.1016/j.rser.2015.07.031

[4] ZAINAL ABIDIN, B. M. Z., KHALIFA, O. O., ELSHEIKH, E. M. A., et al. Wireless energy harvesting for portable devices using split ring resonator. In 2015 International Conference on Computing, Control, Networking, Electronics and Embedded Systems Engineering (ICCNEEE). Khartoum (Sudan), 2015, p. 362-367. DOI: 10.1109/ICCNEEE.2015.7381392 
[5] KIBRET, B., TESHOME, A. K., LAI, D. T. H. Analysis of the human body as an antenna for wireless implant communication. IEEE Transactions on Antennas and Propagation, 2016, vol. 64, no. 4, p. 1466-1476. DOI: 10.1109/TAP.2016.2526070

[6] KUNG, M. L., LIN, K. H. Enhanced analysis and design method of dual-band coil module for near-field wireless power transfer systems. IEEE Transactions on Microwave Theory and Techniques, 2015, vol. 63, no. 3, p. 821-832. DOI: 10.1109/TMTT.2015.2398415

[7] HEKAL, S., ABDEL-RAHMAN, A. B. New compact design for short range wireless power transmission at $1 \mathrm{GHz}$ using $\mathrm{H}$-slot resonators. In Proceedings of the 9th European Conference on Antennas and Propagation (EuCAP). Lisbon (Portugal), 2015, p. 1-5. ISSN: $2164-3342$

[8] SHARAF, R., HEKAL, S., EL-HAMEED, A. A., et al. A new compact wireless power transfer system using $\mathrm{C}$-shaped printed resonators. In 2016 IEEE International Conference on Electronics, Circuits and Systems (ICECS). Monte Carlo (Monaco), 2016, p. 321-323. DOI: 10.1109/ICECS.2016.7841197

[9] MOHD SALLEH, M. H., SEMAN, N., ABANG ZAIDEL, D. N., et al. Investigation of unequal planar wireless electricity device for efficient wireless power transfer. Radioengineering, 2017, vol. 26, no. 1, p. 251-257. DOI: 10.13164/re.2017.0251

[10] PALANDOKEN, M. Compact bioimplantable MICS and ISM band antenna design for wireless biotelemetry applications. Radioengineering, 2017, vol. 26, no. 4, p. 917-923. DOI: $10.13164 /$ re.2017.0917

[11] VISSER, H. J. Indoor wireless RF energy transfer for powering wireless sensors. Radioengineering, 2014, vol. 21, no. 4 p. 963-973. DOI: 10.13164/re.2017.0963

[12] HEKAL, S., ABDEL-RAHMAN, A. B., ALlAM, A., et al Asymmetric strongly coupled printed resonators for wireless charging applications. In IEEE 17th Annual Wireless and Microwave Technology Conference (WAMICON). Clearwater (FL, USA), 2016, p. 1-5. DOI: 10.1109/WAMICON.2016.7483829

\section{About the Authors ...}

Rasha HUSSEIN was born in Qena, Egypt. She received her B.Sc. in Electrical Engineering, Electronics and Communication from the South Valley University, Egypt, in 2015. She is currently working as a teaching assistant at the Electrical Engineering Department, Qena Faculty of Engineering, South Valley University. Her research interests include antenna design, filter design, and wireless power transfer (WPT) for biomedical implants and electronic devices.

Hany A. ATALLAH was born in Qena, Egypt. He received his B.Sc. and M.Sc. in Electrical Engineering, Electronics and Communications from the South Valley Uni- versity, Egypt, in 2007 and 2012, respectively, and the $\mathrm{Ph} . D$. degree in Antennas and Microwave Engineering at Egypt-Japan University for Science and Technology. He is currently working as an Assistant Professor at the Electrical Engineering Department, Qena Faculty of Engineering, South Valley University. He was a Visiting Researcher with the E-JUST Lab, School of Information Science and Electrical Engineering, Kyushu University, Japan, from September 2015 to July 2016. He is a reviewer for Applied Computational Electromagnetic Society (ACES) Journal, Advanced Electromagnetics (AEM) Journal, and Progress in Electromagnetics Research (PIER) journal. His research interests include antenna design, dielectric resonators, metamaterials, reconfigurable antennas, and filters. His recent research has been on cognitive radio (CR) antennas, wireless power transfer (WPT) for biomedical implants, electric vehicles, and electronic devices, breast cancer detection, smart meters, and internet of things (IoT).

Sherif HEKAL received the B.Sc. and M.Sc. degrees in Electronics and Communications Engineering from Benha University, Cairo, Egypt, in 2007 and 2012, respectively, and the Ph.D. degree in Electronics and Communications Engineering from the Egypt-Japan University of Science and Technology, Alexandria, Egypt, in 2016. His Ph.D. was a joint program with the Faculty of Information Science and Electrical Engineering, Kyushu University, Fukuoka, Japan. He joined the Motorola Company Ltd. and Nokia Siemens Networks as a Communications Engineer, where he was involved in $2 \mathrm{G} / 3 \mathrm{G}$ RF optimization. He is currently an Assistant Professor with the Department of Electronics and Communications Engineering, Faculty of Engineering, Shoubra, Benha University, Cairo. His current research interests include antennas, wireless power transfer, and energy harvesting systems.

Adel B. ABDEL-RAHMAN was born in Aswan, Egypt, in 1968. He received the B.Sc. and M.Sc. degrees in Electrical Engineering, Communication and Electronics, Assuit University, Egypt, in 1991 and 1998, respectively, and the Ph.D. degree in Microwave Engineering at the University of Magdeburg, Magdeburg, Germany. He is currently working as Prof at the E-JUST, Alexandria, Egypt - on leave from the South Valley University, Qena 83523, Egypt. His research interests include the design and analysis of microstrip antennas, filters, and their application in WLAN and mobile communication. His recent research has been on cognitive radios, wireless power transfer, and on-chip antennas. 